\title{
THE HIPPIES IDENTITY IN THE 1960S AND ITS AFTERMATH
}

\author{
Nafisatul Lutfi \\ nafienevan@gmail.com
}

\begin{abstract}
The study on the hippies is abundant in numbers but not many of them study the disposition and identification of the hippies during the 1960s and its aftermath. Pierre Bourdieu's theory on cultural practice, theory of hybridity, and globalization are used in this research to investigate the disposition and trans-nationality of the hippies in order to search for their universal identity. A Transnational American Studies approach is implemented to cover the following issue: (1) the socio-cultural disposition of the hippies in the 1960s, (2) the influence of European movement to the American Hippies, (3) the cultural hybridity of the hippies in relation with India, and (4) the similarities of the hippies and the reasons behind it. This research used library research and document analysis method in gathering the data whereas descriptive analysis approach is also used to analyze the data. The United States of America, India and Germany are the three countries being studied in relation to the hippies in the 1960s. The finding shows similar dispositions or background among the hippies in some countries being studied as well as some similarities and differences in the cultural practices of the hippies in the countries being studied. This shows the transnationality of the hippie's identity and the influence of hybridity and globalization which causes the shifting of ideology and cultural practices of the hippies in its developments.
\end{abstract}

Keywords: hippies, identity, Pierre Bourdieu, habitus, hybridity, globalization, Transnational American Studies

\section{INTRODUCTION}

Identity is an important thing for human life. It defines disposition and it indirectly directs action regarding the reality of their world. The term identity relates to "cultural descriptions of persons with which we emotionally identify and which concern sameness and difference, the personal and the social" (Wise, 2007, p. 4). It relates with the term distinction with which we are able to identify ourselves and identified by others. Identity also is closely related with values and ideology. An item of value is something to which we ascribe worth and significance relative to other phenomena. Cultural studies has been concerned with questions of value in relation to (a) aesthetics, (b) political and cultural objectives and (c) the justification of action (Baker, 2004, p. 206).
Values thus differentiate between what is right and what is wrong in the three dimensions mentioned before. It is also closely related to the term ideology which according to Loewenstein (1953) puts more emphasize on the "consistent integrated pattern of thoughts and beliefs" which "explains man's attitude towards life and his existence in society" (Gerring, 1997, p. 958). The values that are practiced by a group of people for a long time and have been embedded in their very action can give birth to an ideology. When taken in cultural context, it is closely related to the Marxist idea that ideology basically tells about class relations although for Gramsci ideology is grasped as ideas, meanings and practices which, while they purport to be universal truths, are maps of meaning that support the power of particular social classes 
(Baker, 2004). Ideology then turns into power which can be used by anyone given the necessary elements which make it constantly change through time and space.

The 1960s has been a landmark in American history regarding the study of identity formation, battle of values and ideology. It highlights the birth of civil empowerment in the form of rapidly changing socio cultural values. Not only that it gave birth to the bigger major movements such as feminism, anti-racial discrimination, freedom of speech and expressions, it also brought a massive changing of the lifestyle of youth at that time which defined their identity. The 1960s was a decade of protests and movements to change society which challenged the nature of ideology and its power mechanism between the minority and the majority.

Hippies are one of the few groups which played a significant role in the counterculture movement of the 1960s. The hippie subculture was originally a youth movement that began in the United states (San Francisco) in the middle of the 1960s which then spread around the world (Viota, 2013). The word hippie derives from hipster (Sheidlower, 2007). Hippies were young people, about 25 years old, mostly from rich families, who rejected their way of life and materialistic system of values. They left comfort, elegance, shallow adult ways of life and they chose a simple, rustic and natural life. They wanted to batter down boundaries: national, race, religious, sex and other diferences. Hippies are closely related to the terms: vegetarians, nudists, intercede for natural medicine, clothing reform, sexual reform, economic, social, cultural and religious reforms and freedom for children, women and animals.

Hippies were powerful to the point that they could gather thousands of people to join their 'camaraderie' in the Summer of Love festivals and Woodstock festival in the 1960s which became a landmark of history. Their lifestyle also became an inspiration for the youth around the world even until now. Through the Hippie Trail journey to the East looking for the real freedom, they spread their new values to the world which ended in Goa India. Hippie subculture with its controversies of good and evil and its strong influence on the society at that time are thus an interesting object to be studied. The unorthodox ways of life which are considered as revolutionary during the era makes us question the process of how the subculture emerged into the society and became one of the most influential groups in the Counterculture Movement of the 1960s both inside and outside America.

This research thus aims to search the possible alternative ways to study about the emergence of this subculture using Pierre Bourdieu's theory of Social Practice based on his book Distinction: A Social Critique on the Judgment of Taste (1984). Bourdieu's theory on the distinction of taste views a subculture not just as a resistance (from the dominated) to the mainstream (dominating) but more of a process of individual negotiations in the term of cultural capital (Williams, 2007). It involves a heavy process of searching for the identity of the subculture members. A Transnational American Studies approach is thus implemented to cover the following issues: (1) the socio-cultural disposition of the hippies in the 1960s, (2) the influence of the European movement on the American Hippies, (3) the cultural hybridity of the hippies in relation to India, and (4) the similarities of the hippies and the reasons behind it.

\section{LITERARY REVIEW}

Several writings taking Hippies as the object of study have been gathered. According to the research, the hippies are mostly seen as a historical phenomenon and sometimes seen as 
a resistant action done by the youth to oppose the established government of that era. Some studies which include hippies as their object of study are merely related to the study of symbol in Volkswagen Bus, hippies related to rock music (Covach, 1966 - 1976), the hippies and their legacy (Tsimpouki, 2014), the roles of the hippies, etc. It is hard to find an analysis which studies hippies as a subculture which also implements Pierre Bourdieu's cultural practice theory and habitus. That is why, the researcher believes that this study is the first to use Bourdieu to explain the hippie phenomenon.

In the term of the implementation of Bourdieu's analysis to a subculture phenomenon, the researcher found some analyses which use the same theory. Some of them are the study of youth Punk Culture (Fox, 1987), study on Goth subculture in Finland (Tolonen, 2007), the study of youth subculture by Cohen (Cohen, 1972) and The Investigation of the Hipsters by Anne W. Rasmussen et. al (2012). The most similar study with this research is the study of the hipster since its subject (hipster) is sometimes considered as part of the revolution of the hippie generation of the 1960s. The study of the hipster mentioned that the hipster phenomenon exists as an attempt by middle class youth to gain cultural capital in terms of symbolic power of hipster fashion. The hipster youth cannot gain enough economic capital to acquire the lifestyle and value of the higher class youth. They then create an alternative ways of creating a fashion which then spread to the rest of the world by the use of media and internet to show their distinction and uniqueness which will then elevate their position in the social cultural field. The elevation happens due to the wide acceptance of the uniqueness or the hip factor of their style which later on, the higher class tries to acquire by simply taking the part of the hip fashion as they like it. The best example is the use of hipster accessories by Paris Hilton and other popular artists. However, the research which specifically uses Bourdieu's habitus theory to describe the hippies has not yet been found. Thus, this research is considerably new and fresh.

\section{THEORETICAL CONSTRUCT}

The identity of the hippies is reflected by its distinct cultural practice. In an attempt to define its identity the study of practice becomes an essential part of this research. Within the theory of habitus by Pierre Bourdieu, practice itself is considered to be the result of a social agent's disposition (habitus) and that social agent's acquired power (volume and form of capital), all within the social space (field). Agents' actions are determined by both the range of options available to them (field and capital) and their disposition (habitus). A field is a social space where agents (individuals or groups) interact, participating in exchanges and events. Capitals, on the other hand, are the resources that agents compete to acquire and, through their acquisition, gain power and/or social standing. Whereas the forms of capital ranges from economic (having monetary resources), social (having the "right" social network), and cultural (having knowledge), Habitus is the generative scheme (or set of dispositions) that agents acquire primarily in their childhood, but also in other social contexts. The interplay of the capitals in shaping the identity of the hippies which is reflected by their cultural practice is the catalyst which this research dwells upon. The discussion mainly covers how the interplay of the capitals owned by the hippies highlight the reasons and process behind its emergence in the 1960s.

As mentioned in the introduction above, the hippies here now spread all over the world and they have undergone some shifting both in their cultural practices and identification. 
The distorted image between the hippies in the 1960s and the present can only be described through the notion of hybridity. Hybridity involves the mixing together of previously discrete cultural elements to create new meanings and identities. Whereas the spread of the hippies ideology and the people themselves is inseparable with the notion of globalization which becomes the bridge which interlink the elements together. In relation to globalization, diaspora cultures and post colonialism, hybrids destabilize and established cultural boundaries in a process of fusion or creolization. Each category is always already a hybrid form which is also divided along the lines of religion, class, gender, age, nationality and so forth. Avtar Brah in Hussain (2004) stated that borders are "arbitrary dividing lines" which function on a social, cultural and psychic level. As such they are always metaphors and "part of the discursive materiality of power relations". Hippies, in this term, are the hybrid of which origin might be nonexistent.

Globalization provides the context for an increased range of sources and resources available for identity construction. Globalization itself refers to "social, economic, cultural, and demographic processes that take place within nations but also transcend them". In this term, we are dealing with "the intensification of worldwide social relations which link distant localities in such a way that local happenings are shaped by events occurring many miles away and vice versa" (Kearney, 1995, pp. 547-565). The concept of globalization refers us to the increasing multi-directional economic, social, cultural and political connections that are forming across the world and our awareness of them. (Baker, 2004). Thus, identities are never either pure or fixed but formed through the articulation of age, class, gender, race and nation which transfers through globalization (Baker, 2004, pp. 8990).

As globalization occurs, border and space become absurd in a way that eliminates the border, making the world interconnected. Space, in this term, has to be understood as a multidimensional entity comprising notions of territorial dimensions as well as social and cultural characteristics. In this term, it both includes the physical space as in land or the nonphysical one, as in ideology. Hussain (2004) stated, "the applied perspective of space signifies the clearly operating colonial discourse which establishes the borders of Inside and Outside; thus, hybridity simultaneously refers to the potential border crossings through the adaptation of a westernized view of the world" (p. 110).

\section{METHODOLOGY}

In order to reach the objective of the research, this study uses a library research method which focuses on document analysis. The focus of the study is the examination of documents, thus, the researcher should have access to such material which may include letters, memos, notes, diaries, photographs, audiotapes, videotapes, films, articles, books, manuscripts, e-mails, online discussions and so forth. In general documents are any preserved recording of a person's thoughts, actions or creations (Potter, 1996). The examination of documents is especially important to historians who investigate patterns and trends from the past. Documents may be examined to investigate patterns and trends of the past as is commonly done by historians. If no humans remain alive to provide primary evidence, then documents are the in only source of data (Potter, 1996). Documents are also examined by researchers who are investigating subjects who are available. The examination of documents may also provide confirmatory evidence of the 
information obtained from interviews and observations. The data being collected then analyzed and categorized based on its clusters and then analyzed to answer the objective of the research which mainly focuses on describing the hippie's emergence during the 1960s and the possible explanation about it and the transformation of their identity which underwent changes and border crossing processes which gave birth to the hippies that we know now.

\section{DISCUSSION \\ THE DISPOSITION OF THE HIPPIES IN THE 1960S}

It is generally acknowledged that the sixties inherited the surge of prosperity from the growing industrialization of the fifties. The growing factories and the escalating rate of employment of the fifties gave the sixties the notion of the Age of Plenty which referred to the abundant life of the American people. The number of Middle Class people escalated and they become the majority in terms of numbers. This situation called for various kinds of circumstances which led to the birth of the hippies among these new Middle Class groups. This subchapter describes the link between the hippies and the fact that they mostly came from this particular class instead of the others.

They were middle class people who owned sufficient economic capital in terms of income, social capital in terms of network, cultural capital in terms of education and symbolic capital in terms of the consumptive goods they possessed in their homes. Secondly, the number matters. The amount of people in the middle class in the 1960s was comparatively bigger than in the other two classes. This era was the era that created the first mass middle class in the world - a middle class that even factory workers could enter, since they could earn relatively comfortable livings even without high levels of education or professional skills (Teixeira \& Abramowitz, 2008, p. 4).

In addition, the stronger and the bigger the community that one joined, the bigger symbolic and social capital they had, the more significant they felt in their disposition when it became an important capital in that era (prosperous 1960s and 1980s). It relates to Bourdieu's theory on disposition: one will feel at home when they feel comfortable with their disposition no matter what and where their disposition is. The 1960s has an era with plenty of economic capital and cultural capital for the middle class. They had prosperous lives with no worry about spending their money for whatever they wanted as well as a proper education which they could gain since their parents did not force them to work and they could afford their tuition fee (Paglia, 2003, p. 94).

In summary, the reasons which related the hippies and the middle class were their fluidity within the liminal space which enabled them to move back and forth between the other two classes and their comparatively bigger number than the other two classes which enables them to build a strong community with meaning behind it. This added to their fair share of circumstances during the 1960s and 1980s about the war, 'unreliable government, pressure from conservatism and the other alternatives gained from the media and their education which will be explained in the later part of this chapter.

The discussion on the middle class above might apply to the U.S and Europe in general but truth be told, it is not so when we bring India into the context of this discussion. India was considered as less fortunate in terms of 
economy compared to the two other nations discussed in this thesis. As mentioned in the introduction, India is included in this discussion to find the identity of hippies beyond borders. However, the hippies in India were not Indians, they were the whites migrating to seek the exotic and mythical India prior to the 'decline' of the hippies in Europe and the U.S in the 70s. The rate of the migration was huge and reached to the amount of 500.000 people coming from various countries in Europe and the Americas (Luthie, 2006). Some of them left and some are still living their values today in the quiet side of Goa, the hippie heaven in India.

It is often questioned whether African Americans fall into the discussion of hippies or not. Where were they when the counterculture happened and why did not they join the hippies in the first place? The answer to these question can be: (1) they were too busy with their civil rights causes, (2) they did not have the same fluidity as the white middle class, in the sense that they did not have as many options as the white middle class, and (3) they already had a strong sense of community and shared belief within their own groups with their own symbolic capitals reflected in their already unique cultural practices of lifestyle, or they simply could not blend with the majority white middle class with the circumstances and the struggle of equality in various aspects of American life. At the time, last but not least there may have been some African Americans within the crowd at Woodstock, they were simply not notice.

\section{THE YOUTH DEMOGRAPHIC CHANGE AND THE HIPPIE}

The hippies of the 1960s were mostly youth (Kunkel, n.d., p. 12). The exact numbers of the youth joining the hippies is hard to obtain due to the mobility of the members. Youth were the ones with the access to the 'truth' of the circumstances they lived in and the alternatives that they could run in to both from campus and media. By the circumstances here means the social and political conditions of the era. The second thing to be noticed about the sixties is the demographic change of the youth, their numbers compared to their parents (Baby Boomers). By the 1960s, the student population had rocketed. In 1960, 22 per cent of young people were students, by 1975 it was 35 per cent (Bailis, 1974, p. 174). The huge amount of youths in the 1960s meant an increase in student enrollment, which correlated with the rise of the middle class due to the high rate of employment in the industries of the post war era. It is mentioned that some colleges and universities were so overloaded with students that they needed to build new buildings and make new regulations to accommodate them (Stone, 1999, p. 35).

\section{THE CLASH OF OLD AND NEW VALUES AND HOW IT INFLUENCED THE HIPPIES}

The 50s was the age of prosperity for Americans for two reasons. First, the war did not happen in the continent but far away in Europe and Asia which left America unscathed, and second, the winning of the war and the fact that they survived the damage it caused implies that Europe and the rest of the world relied on America for their reparation. Industry and business flow to America triggered significant economic growth within the nation and the prosperity for its people with the Inflation-adjusted per capita disposable income increased by 36 percent over the decade. Unemployment fell steadily throughout the decade, declining from 5.5 percent in 1960 to 3.5 percent in 1969 (Podesta, 2004, p. 2).

Technology has changed human life rapidly. The invention of electricity and the telephone already changed the face of the society. New 
technology also gives new opportunities for developments and new insights. It often becomes the source of a generation gap between the old and the new generation. The same thing happened during the emergence of the hippies in the 1960s in America, Germany and India. This subchapter highlights the prominent technological changes which contributed to the emergence of the hippies in the 1960s. Technology and the convenience it contributes to the habitus in the form of both economic capital and social capital. Economic capital highlights the notion of possession of convenience stuff whereas social capital relates with the role of technology in strengthening the network of the hippies.

In the U.S in the $1960 \mathrm{~s}$, the most prominent technological invention which contributed to the emergence of the hippies was the invention of contraceptive pills, the invention of LSD and other psychedelic drugs and the development of media and recording. Contraceptive pills contributed to the changing of youth attitudes towards sex which became one of the most important aspect in hippie lifestyle. Whereas LSD brought a new experience to the state of bliss which the hippies sought in order to achieve a psychedelic experience. Television, as always, gave new insights and information on the things happening around the world and contributed to the spread of the hippie movement. The freedom of sex became more reasonable when contraceptive pills were invented in the 1960s with the commercial release of Enovid, the first reliable oral contraceptive in history which overwhelmed the sixties' spiritual quest of free love (Paglia, 2003 , p. 82). When it was introduced as birth control to the baby boomers, it was supposed to be for married couples. However, the youth finally got their hands on the pills and used them as an excuse to legitimize sex as something which you can do with anyone you love. Back then in the 50s, sex was considered as a thing that should be done by married couples and it was a taboo thing to talk about (Stone, 1999, p. 16). Hippies, having learned that sex was in fact something sacred related to their rites, used the safety it provided to nullify the elders arguments regarding sex.

Hippies, in fact, received many influences from other countries around the world. As what has been mentioned in the chapter on the development of the hippies, the cultural practice of the hippies was a hybrid of many other cultural practices either from the East or the West. The popular way of spreading the hippie idealism was with the help of the rapid development of technology. It related to the media and how it changed the face of the communication in the world. By 1960s, almost every house in the U.S and Europe had a television set in the living room (Podesta, 2004, p. 4). It is true that television has indeed turned the world, according to McLuhan, into a global village in which everything is transfixed and mixed into one another with the disappearance of borders and limits (Paglia, 2003, p. 93).

\section{THE WARS AND THE HIPPIES' CAUSE}

As mentioned in the passage above, the circumstances of the agents, which acted as the outer factor in the agent's, middle class youth's, habitus played a significant role in the emergence of the hippies despite their social class and capitals. The circumstances mentioned above included the wars which loomed over the Americans at that time. The threat of Nuclear War, the Cold War and the Vietnam War subsequently became their monsters under their beds. This chapter will explain the kinds of threats faced by the U.S which became one of the important factors in the emergence of the hippies in the 1960s.

The Civil Rights movement can be seen as the cornerstone for the counterculture movements 
of the 1960s. It all began with a woman who refused to sit at the back of a bus and a man who are refused to eat his lunch elsewhere just because they were black. The movements for civil rights that spread across the U.S inspired thousands of people in the way that it woke up their sense of disposition, their perception on the reality they lived in. It also set an example of the ability of the people to break off the established doxa and fight for their own rights to strengthen their disposition in the American society.

The importance of the movement to the hippies itself is almost the same in the way that it inspired them to have the guts to stand up and fight for their right. When the movement started it gave the youth a new set of classifications in which they could reformulate their disposition. The oppressed and the oppressor's state become so apparent that the injustice that the oppressed had to live by had materialized in the real world, it was not a denied myth anymore. Within the process of classifying the oppressor and the oppressed, the hippies put themselves in the later one's category but chose a different way to flip the table.

\section{THE TRANSNATIONALITY OF THE HIPPIE'S IDENTITY}

The notion of identity can be described in two processes: self-identification and how you are identified by others (Baker, 2001). The study of hybridity and globalization are implemented to show the process and mechanism of the identification of the transnatioanlity of the hippies in the $60 \mathrm{~s}$, before and after.

Hippies seem to have similar traits which lead to an accepted definition given to the all members of movement. They commonly relate to the youth, drugs, unique fashion, naturalists and alternative life supporters.
Some accounts on the hippies are made based on those similarities. Although the hippies nowadays refers to the unique lifestyle represented in their cultural practices, the hippies used to refer to the 60s hippies in the U.S.A and the strong ideology they represented. This subchapter deciphers the similar practices of the hippies in three nations: the U.S, Germany and India. The similarities found in this research are analyzed in terms of whether they represent American values or global values. The result of the observation on the values may either support or negate the power of Americanism through its popular culture and capitalism across those three nations.

The first striking similarity of the hippies in the three countries being analyzed is the age of the hippies themselves. It is apparent and has been mentioned everywhere that the hippies are mostly youth between teen age to the middle age (16-30s). This brings up the notion that has became youth becomes closely related to the hippies. The similar age involved in the hippie movement in the three nations studied shows the importance of the age to the identification of a hippie despite the fact that there are lots of hippies with varying ages around nowadays. Fashion becomes one of the tools to rebel against the mainstream culture that the hippies loathed in the sixties. Stone in his book even mentioned that the true hippie ideology is expressed through the clothing choice. He stated that

...no self-respecting hippie ever wore a logo of some corporation. This was heretical to the hippy movement. It's no wonder so many kids today, sick of having to conform to corporate ideals of fashion have instead sought out the Hippy Brand ${ }^{\circledR}$ of non-conformist, antiestablishment, revolutionary, laid back sportswear! No logos, no commercials with sports figures, no multi- million dollar endorsements, no hype. Just 
cheap, comfortable, easily repaired, second-hand clothes to give you the look (Stone, 1999, p. 26)

The statement by lifestyle is mentioned by Bourdieu as a means to strengthen their symbolic capital by increasing their distinction which will then in turn enable them to spread their ideology even more. The same thing seems to be persistent with the Indian hippies as well. Their famous clothing style has became one of the reasons why tourists are still flocking to the Flea Market in Goa. Through their commitment to staying close to nature despite the heavy consumerism of that era in Germany, the Wandervogels deliberately tried to get closer to nature by taking "long hikes in the country where they sang their own versions of Goliardic songs and camped under primitive conditions" (Kennedy and Ryan, 2009, pp. 7-8) which then was followed by the commune in Ascona as the pioneer of the $60 \mathrm{~s}$ communes in the U.S.

Some practices that were common among the hippies of the 60s such as both sexes swimming nude together in the lakes and rivers were "common at that time as well as 'establishing nests' and 'anti-homes,' sometimes in ruined castles where they met to plan trips and play mandolins and guitars" (Kennedy \& Ryan, 2009, pp. 7-8). It shows that the tradition of establishing communes and indulging in music while bathing nude that were done by the hippies in the 1960 s America were rooted in what had been practiced by the Wandervogels in $1890 \mathrm{~s}$ Germany.

The use of drugs by the hippies was mostly aimed toward reaching the psychedelic trance with which they could escape from the society they disagree with many levels. It might be true that drugs are a means of escaping from reality but the hippies believed that taking drugs much more spiritual in a sense, although not internally religious, rather than for leisure or practical use. In the Look of American Life in the 60's Especially it's music, it is mentioned that "Drugs, especially entheogens, played an important factor in the hippie culture". By the use of drugs they managed to "contrast the hippies within the society and intensify the counterculture while they enabled the Hippies to have psychedelic experiences" (p. 5). In this term, drugs are a means to reach the psychedelic trance as well as to 'fight' against the 'corrupt' mainstream culture. When someone visits Goa, the music they will be listening to is the trance music in the clubs and beach parties. Andi (adJ in Goa) stated that

In Goa, trance means trance which is designed to be danced, and to be listened to, while you're tripping. You know. And everybody else has to stand back. Because who is dancing the whole night, who is dancing the longest, is the people tripping. (Saldhana, 2006, p. 18)

Partying has been an integrated part of the hippie lifestyle. If we take notice of the gathering of hippies all around the world, it is partying and dancing to trance music which has became their main activity. From Woodstock to the latest Aozora festivals, what pulls people all around the world to join them is the never ending partying and having fun. A hippie must know how to party hard.

Festivals were said to begin in the late $60 \mathrm{~s}$ with the many free concerts held by musicians in the U.S relating with the counterculture movement of 1960s America. It reached its peak with Woodstock and then gained more popularity with the media coverage and the amount of youth attending the event. More free concerts and festivals were held including Summer of Love Festivals in the U.S and 
Britain, the festivals in Berlin, France, and others. Helped by television as the main media for spreading of Popular Culture, festivals became attached to the hippie identity.

\section{HYBRIDITY AND GLOBALIZATION OF THE HIPPIES}

As it was mentioned by Kearny, globalization is characterized by "the intensification of world-wide social relations which link distant localities in such a way that local happenings are shaped by events occurring many miles away and vice versa" (Kearney, 1995). If in the past the notion of cultural fusions can only happen when people move from one place to another, nowadays, the exchange of culture is made easier with the invention of media especially television and the internet.

The globalization process in Goa began when the hippies migrated to Goa, which was due to the Lonely Planet article about it which spread all over the world. It was mentioned in the New York Times on the hippie trail to Goa that the hippies of the 70s were "Seduced by the beaches with no tourist, green jungle, dramatic cliffs" and decided to ride on the "magic buses" from Europe and created "a free-spirited, budget-friendly new world among the laid-back native northern Goans". It is the free-spirit and the laid back attitudes of the natives which seduced the hippies. In addition to, the exotic nature of the land itself. The wilderness and the nature which represented their ideology of freedom and love made them want to move there. As an effect, they influenced the locals with their activities and made the quiet place, "the village of Anjuna becomes its wildly spinning center, with the quieter communities of Arambol and Vagator emerging as hemp-clad satellites" (Sherwood, 2006, p. 2)
Globalization also played an important role in the spread of Indian spiritualism in the U.S. When the hippie colonization of Goa reached its peak and more American hippies searched for gurus in India in the sixties, a certain Maharaj Ji, who claimed to be the successor of Jesus and Buddha, decided to visit America (Paglia, 2003, p. 78). It is mentioned that the Divine Light Mission was brought to the U.S in 1971 by thirteen-year-old Maharaj Ji of which philosophy required vegetarianism, celibacy, and meditation, which became so popular at that time due to both its unique values and its contrasting difference with the major culture that the hippies loathed at that time.

The notion above shows that the flux of globalization moves back and forth with both sides of the world influencing one another. The events in India influenced what happened in America and vice versa which then gave birth to the development of certain teachings such as The Divine Mission which claimed to have 480 centers in thirty-eight countries. "By 1973, there were thirty-eight ashrams in the U.S. with 40,000 followers" (Paglia, 2003, p. 78).

\section{CONCLUSION}

The finding shows that there are three major ideologies found in the cultural practices of the hippies. They are freedom, love and peace. Those ideologies always appeared and became the justifications of their weird cultural practices in the sixties by mentioning that flowers represented their faith in peace and not war and tie die shirts and long hair represented the freedom they sought. This makes the hippies appeal to the youth more than the elders due to the bold symbolism it represents. This kind of mechanization of ideologies embedded in cultural practice apparently blurs the line between ideology and lifestyle. One might wear a tie die shirt 
and grow his hair long but he does not necessarily have the ideology of freedom. The same thing goes when one embraces vegetarianism as a lifestyle, because it might be related to a health reason more than to the idea of living in harmony with nature.

It has been mentioned in several sources that the hippies actually represent the ideology of peace, love and freedom (Stone, 1999). During its "emergence" in the 1960s this ideology becomes the appealing point of this subcultural phenomenon. According to the discussion in the previous chapter, those three core ideologies and values are the ones which are most suitable to surge regarding the condition of that era. Freedom, peace and love they represented with their unique cultural practices. The freedom of love was represented in the freedom of sexuality in which one is free to love anyone with any kind of background and with no boundaries. Whereas the freedom in life they represented in their slogan of "Turn in drop out" which encouraged the youth to leave home and stay in the communes with the people of their kind. The peace was represented with the flower they used in the marches to stop the war along with the iconic symbol of peace drawn in Fidus' painting and the bright colors of their tie die shirts and long hair. While the real peace they could seek in their psychedelic trance with the help of drugs and music in which they could see the ideal world free of war, confines and hatred. The adoption of foreign cultures from around the world can be categorized as their attempt to strengthen their symbolic capital by the technique of distinction proposed by Pierre Bourdieu.

Becoming different and against the mainstream culture became one of the appeals of the hippies which attracted thousands of youth followers in the 1960's America and the aftermath. Hippies ideologies become blurry and gone through time as well. The adoption of culture instantly to show someone's distinction which will then increase his symbolic capital becomes the cause of it. It can be seen from the adoption of culture by the hippies in terms of fashion which now is considered as the hipster fashion. Seen as the reincarnation of the sixties hippies, the hipster fashion has become popular and everyone can wear it and be identified as peace loving hippies (Rasmussen, Boas, King, and Madsen, 2012). The rebellion against on the conservative majority culture and values at that time was well represented in their indulgence in their unique fashion such as long hair, bright and colorful clothes, and the wearing of ethnic and eastern accessories such as jewelries and head bands as opposed to the crop short hair of the military, sleek and pastel colored clothes of the rich, and prim and simple but luxurious popular accessories of the sixties. However, nowadays, any artist without care about the basic ideology of what they are wearing can sport the hippie style whenever they want to be identified as one, who holds the same ideology as the hippies.

\section{REFERENCES}

Anne W. Rasmussen; Caroline Boas; Laura King; Troels Bo Haarh Madsen. (2012). Investigation of the Hipster. Roskilde: Roskilde University.

Bailis, S. (1974). The Social Sciences in American Studies.

Baker, C. (2001). Cultural Studies and Discourse Analysis: A Dialogue on Language and Identity. London: Sage Publications Ltd.

Baker, C. (2004). The SAGE Dictionary of Cultural Studies. London: SAGE Publication.

Cohen, P. (1972). Subcultural Conflict and Working Class Community. Cultural Studies Journal, 5-51.

Covach, J. (1966 - 1976). The Hippies Aesthetic: Cultural Positioning and Musical Ambition in Early Progressive 
Rock. Composition and Experimentation in British Rock.

Fox, K. J. (1987). Real Punks and Pretenders: The Social Organization of a Counterculture. Journal of Contemporary Ethnography vol.16, 344 -70 .

Gerring, J. (1997, December Vol.50 No.4). Ideology: A Definitional Analysis. Political Research Quarterly, pp. 957994.

Kearney, M. (1995). The Local and The Global: The Anthropology of Globalization and Trasnationalism. Anthropol, 547-565.

Kennedy, G., \& Ryan, K. (2009, October 24). Hippie Roots and the Perennial Subculture. Retrieved April 25, 2014, from www.hippy.com.

Kunkel, F. (n.d.). The Hippie Movement.

Luthie, U. G. (Director). (2006). Hippie Masala Forever in India [Motion Picture].

Paglia, C. (2003). Cults and Cosmic Consciousness: Religious Vision in the American 1960s. Arion 10, 57-111.

Podesta, M. (2004). 1960s Family in America. Boston: New England Economic Adventure.

Potter, W. (1996). An Analysis of Thinking and Research about Qualitative Methods. Mahwah: New Jersey: Larence Erlbaum Associates.
Sheidlower, J. (2007, May 7). Crying Wolof: Does the Word Hip Really Hail from a West African Language. Slate Magazine.

Stone, S. (1999). Hippies from A to Z: Their Sex, Drugs, Music, and Impact on Society from the Sixties to the Present. New Mexico: Hip Inc.

Teixeira, R., \& Abramowitz, A. (2008). The Decline of the White Working Class and the Rise of a Mass Upper Middle Class. The Future of Red, Blue and Purple America, .

Tolonen, T. (2007). Social and Cultural Capital Meets Youth Research: A Critical Approach. Youth and Social Capital.

Tsimpouki, T. (2014). The Sixties are Dead: Long ive Their Legacy: The Politics and Poetics of Counterculture. Greece: University of Athens.

Viota, J. C. (2013, December 30). Hippie Movement. Retrieved from slideshare.com.

Williams, J. P. (2007). Youth Subcultural Studies: Sociological Traditions and Core Concepts. Sociology Compass, 527-593.

Wise, D. L. (2007, May 23). Identity Theory: A Literature Review. Retrieved from debwise.com:

debwise.com/Matrix_2_files/wise_ident ityLR-1.pdf 